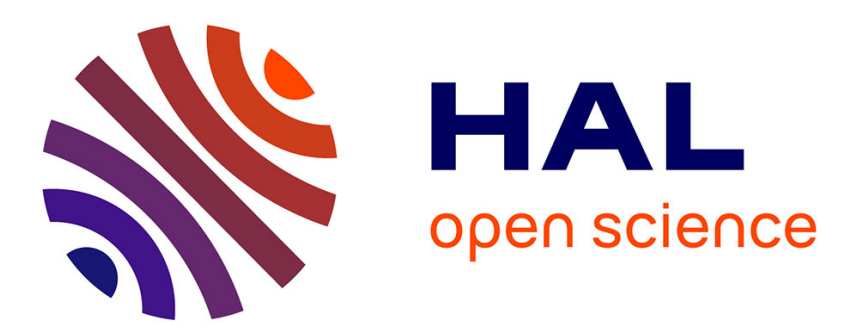

\title{
Experimental Evidence on the 'Insidious' Illiquidity Risk
}

Damien Besancenot, Radu Vranceanu

\section{To cite this version:}

Damien Besancenot, Radu Vranceanu. Experimental Evidence on the 'Insidious' Illiquidity Risk. 2011, pp.27. hal-00607867v2

\section{HAL Id: hal-00607867 \\ https://essec.hal.science/hal-00607867v2}

Submitted on 21 Feb 2013

HAL is a multi-disciplinary open access archive for the deposit and dissemination of scientific research documents, whether they are published or not. The documents may come from teaching and research institutions in France or abroad, or from public or private research centers.
L'archive ouverte pluridisciplinaire $\mathbf{H A L}$, est destinée au dépôt et à la diffusion de documents scientifiques de niveau recherche, publiés ou non, émanant des établissements d'enseignement et de recherche français ou étrangers, des laboratoires publics ou privés. 


\section{Experimental Evidence on the Insidious IIliquidity Risk}

\section{Research Center \\ ESSEC Working Paper 1107}

\section{1}

Damien Besancenot

Radu Vranceanu 
February 17, 2013

EXPERIMENTAL EVIDENCE

ON THE 'INSIDIOUS' ILLIQUIDITY RISK

\title{
Damien Besancenot* and Radu Vranceanu ${ }^{\ddagger}$
}

\begin{abstract}
This paper introduces an experiment aiming to investigate the contribution of illiquidity risk to the total risk of a risky investment project. If implemented, the project succeeds with a known probability. Yet the project fails if the quota of investors is not reached in the first place. Hence strategic uncertainty compounds its effect with the "intrinsic risk" of the project. Results confirm the insidious nature of illiquidity: as long as a first collective default does not occur, investors accept high intrinsic risk projects. After a first default, they become extremely prudent and come back to market only gradually. After several defaults, private agents manage to coordinate on an relatively low intrinsic risk above which they refuse to participate in the project. Macroeconomic policy implications follow.
\end{abstract}

Keywords: Coordination game, Illiquidity risk, Threshold strategy, Experimental economics.

JEL Classification: D81, C92, C72, G20.

\footnotetext{
*University of Paris 13 and CEPN, 99 rue Jean-Baptiste Clément, 93430, Villetaneuse, France. E-mail: besancenot.damien@univ-paris13.fr

${ }^{\dagger}$ ESSEC Business School and THEMA, 105 Av. Bernard Hirsch, 95021 Cergy, France. E-mail: vranceanu@essec.fr.

¥This research was financed by a grant from the Europlace Institute of Finance. The authors would thank participants to the second SER International Conference organized by Nanyang Technological University in Singapore, on 4-6 August 2011, the Annual Conference of the International Trade and Finance Association, Pisa, 20-22 May 2012, as well as Jean-Pierre Choulet, Delphine Dubart, Aurélie Dariel, Karine Lamiraud, Bernard Ruffieux and Estephania Santacreu-Vasut for their suggestions and remarks.
} 


\section{Introduction}

In the past, illiquidity used not to be a top priority on economists' research agenda, who shared the optimistic belief according to which there will always be some deep-pocket investor able to rescue an illiquid but solvent debtor. Yet during the Great Recession of 2007-2009, illiquidity turned into a major factor of economic instability (Pedersen, 2009; Brunermeyer, 2009; Miller and Stiglitz, 2010). In a short lapse of time, in the last four months of 2008, traditional buyers of many asset backed securities and bank commercial paper, almost vanished. Taking one representative quote from The Economist of February 10th, 2010, "Many of those clobbered in the crisis, including Bearn Sterns, Northern Rock and AIG - were struck down by a sudden lack of cash or funding sources, not because they run out of capital." The 2010-2012 turmoil in Euro public debt markets also carries the mark of illiquidity. There is today a widespread consensus among economists and policymakers who acknowledge that illiquidity can originate major disruptions of economic activity.

Classical theoretical papers analyze illiquidity as an inefficient equilibrium outcome that can arise when investors cannot coordinate their actions. The basic rationale was introduced by Summers $(2000$, p.7):

A crude but simple game, related to Douglas Diamond and Philip Dybvig's (1983) celebrated analysis of bank runs, illustrates some of the issues involved here. Imagine that everyone who has invested $\$ 10$ with me can expect to earn $\$ 1$, assuming that I stay solvent. Suppose that if I go bankrupt, investors who remain lose their whole $\$ 10$ investment, but that an investor who withdraws today neither gains nor loses. What would you do? Each individual judgment would presumably depend on one's assessment of my prospects, but this in turn depends on the collective judgment of all of the investors. Suppose, first, that my foreign reserves, ability to mobilize resources, and economic strength are so limited that if any investor withdraws I will go bankrupt. It would be a Nash equilibrium (indeed, a Pareto-dominant one) for everyone to remain, but (I expect) not an attainable one. Someone would reason that some- 
one else would decide to be cautious and withdraw, or at least that someone would reason that someone would reason that someone would withdraw, and so forth. This phenomenon, which Douglas Hofstadter has labeled "reverberant doubt," would likely lead to large-scale withdrawals, and I would go bankrupt. It would not be a close-run thing. John Maynard Keynes's beauty contest captures a similar idea.

If illiquidity is first and foremost a problem of poor coordination of investors, then the theory of order-statistics coordination games can provide interesting insights. In these games, the individual payoff to some action is an increasing function in the number of agents that undertake that action (Carlsson and van Damme, 1993; Morris and Shin, 1998; 2007). The core logic of these $n$ player games can be inferred from the classical two-player 'stag hunt' game, where the fear of lack of cooperation by the other, might prompt players not to adopt the cooperative behavior. Bryant (1983) shows that in a complete information set-up these strategic complementarities result in multiple equilibria with self-fulfilling beliefs. The polar situations where either all players undertake the highest action (the Pareto dominant or payoff dominant equilibrium) or the lowest action (the highest security or minimax equilibrium) are intuitively appealing but cannot be justified on pure deductive grounds. Morris and Shin (1998) work out an elegant solution for equilibrium selection under the assumption that agents do not know the precise payoff of the others but receive private signals that allow them to approximate it. Rochet and Vives (2004) and Morris and Shin (2009) develop models of illiquidity crises in the banking sector. Illiquidity arise if banks cannot roll over their short-term debt due to coordination problems, while insolvency is defined as the riskiness of their long-term investment projects, conditional of not being illiquid at the first stage. They show that partial cooperation can be achieved under imperfect information since Morris and Shin (1998) solution applies. ${ }^{1}$

Many scholars have brought order-statistics coordination games to the Lab, and reached substantial insights. It goes beyond the scope of this short paper to provide a comprehensive survey of these experimental studies; many of them are summarized in Camerer (2003) and Devetag

\footnotetext{
${ }^{1}$ See also Besancenot et al. (2004) for another model of interaction between insolvency and illiquidity risk.
} 
and Ortmann (2007). On the one hand, these studies suggest that the non-cooperative, Pareto dominated equilibrium is rather resilient in games with complete information, a result first put forward by Van Huyck et al. (1990). On the other hand, there are many devices - such as cheap talk, introduction of leaders, former experience with coordination, etc. - that can help engineering better coordination. Heinemann, Nagel and Ockenfels (2009) develop a method to measure aversion to strategic uncertainty in coordination games, similar to standards measures of risk aversion in lottery choices. They show that aversion to strategic uncertainty and risk aversion seem to be correlated among individuals. There are not many experimental studies that study illiquidity as a coordinating failure in a specific investment frame. Schotter and Yorulmmazer (2009) and Madiès (2006) have provided experimental analyses of bank runs; they focus on depositors' decision to pull out their money once that a bank becomes insolvent; Garratt and Keister (2009) analyze the bank run problem in a sequential coordination game, and emphasize the consequences of early withdrawals on the run. .

This paper develops a simple experiment aiming to investigate the contribution of illiquidity (or coordination) risk to the total risk of an investment project. While we take our inspiration from project financing, we avoid using words such as "investment, investor, default" that have their own emotional loading. The basic block is an "investment project" that, if implemented, can deliver either a positive gain or nothing, with a known and predetermined probability. The probability that the project delivers nothing is representative of its "intrinsic risk". Furthermore, if the number of investors who choose to participate to the project is too small ${ }^{2}$, the project will not be implemented in the first place and bring losses to investors, what we refer to as the "illiquidity risk". If the number of investors is large enough, the project is implemented and will succeed or not, depending on the above mentioned probability of success. Hence, in this context, an investor must take into account not only the individual chances that his investment will bring the high payoff, but also the strategic uncertainty stemming from the decision of the other investors. Basically, subjects can pay 20 cents in order to participate to a lottery that brings them 30 cents with a probability $q$ or nothing with probability $(1-q)$. The positive gain (that

\footnotetext{
${ }^{2}$ In this paper, the critical number required for the success of the project will be exogenously given.
} 
occurs with the probability $q$ ) is delivered only if a majority of the subjects have participated to the investment.

Five relatively large groups of subjects (the size of the groups varied from 9 to 16 subjects) were asked to play this game for several rounds, for varying levels of the intrinsic risk $(1-q)$. The risk level was increased in successive steps until a until a first coordination default occurred, then was reduced until coordination was restored, than raised again, following a cyclical pattern. Thus the experiment aims to detect existence of a "threshold strategy" on which players will coordinate their decisions at the term of a learning process. ${ }^{3} \quad$ Requiring people to coordinate on participating to a lottery (hence - an uncertain outcome) is, to the best of our knowledge, an original contribution of this paper to existing experimental literature on coordination games.

The paper is organized as follows. The next section introduces a theoretical benchmark that should help to better gauge subjects' behavior in the experiment. Section 4 introduces the experiment (design and results). Section 5 presents our conclusion.

\section{Theory: The illiquidity game}

To bring some intuition to the experiment introduced in the next section and define the coordination risk, we firstly analyze an elementary imperfect information game where a group of $n$ identical risk-neutral players (where $n$ is an odd number) are invited to play a lottery $L(0 ; 30)$ against an investment of 20 cents. The lottery can pay:

$$
L= \begin{cases}30 \text { cents } & \text { with a probability } q \\ 0 \text { cent } & \text { with a probability }(1-q)\end{cases}
$$

The winning probability $q$ and its complement, the loss probability $(1-q)$ are public information. In order to bring into the picture strategic uncertainty, we impose an exogenously given participation constraint according to which if less than $x \%$ of the players in the group participate to the lottery they all get nothing whatever the outcome of the individual draw.

Given $q$, each player must decide whether to participate to the lottery (strategy $p$ ) or to refrain (strategy $\bar{p}$ ) depending on his own assessment of the actions of the others. In such a game, the

\footnotetext{
3 A concept developped by Heinemann et al. (2004), Heinemann et al. (2009).
} 
optimal strategy $s$ of an individual $i$ consists in choosing a reservation probability $q_{i}^{*}$ and play the game if the actual probability is larger than this critical threshold (and vice-versa), i.e.:

$$
s_{i}=\left\{\begin{array}{ll}
p, & \text { if } q \geq q_{i}^{*} \\
\bar{p}, & \text { if } q<q_{i}^{*}
\end{array} .\right.
$$

While in this game all individuals know the probability $q$ (and $1-q$ ), they might not have the same perception of the illiquidity risk, which depends on the decision of all other players. Each individual $i$ will choose his specific reservation probability $q_{i}^{*}$ depending on his subjective expectation of the behavior of the other members of the group.

Let us order the $n$ players according to their own $q_{i}^{*}$, from the lowest to the highest value. We define as the "pivot player" the player $m$ such that the number of players with $q^{*}>q_{m}^{*}$ represent $x \%$ of the total number of subjects. For an objective risk $q$, if the $m$-individual plays $p$ or "participate" (i.e., $q>q_{m}^{*}$ ), then illiquidity does not arise; to the opposite, if he plays $\bar{p}$, then more than $x \%$ of the players do the same, and illiquidity occurs. It must be noticed that, when taking their individual decision, players should consider only the decision of the pivot player, and not the individual decision of all players. As a consequence, the outcome of this game should not depend on the number of players. ${ }^{4}$

We denote by $F^{i}()$ the player's $i$ subjective c.d.f. of $q_{m}^{*}$.

For a given probability of getting the positive gain in the lottery, $q$, the gain from participating to the illiquidity game $U^{i}(p)$ is obtained by multiplying the positive payoff in the lottery (30) by the individual probability of winning $(q)$ and by the probability that the pivot player participates to the lottery, i.e. that $q_{m}^{*}$ is lower than $q$; this probability is defined for the individual $i$ as $\operatorname{Pr}^{i}\left[q_{m}^{*}<q\right]=F^{i}(q)$

$$
U^{i}(p)=30 q F^{i}(q)
$$

We notice that $U^{i}(p)$ is a monotonous increasing function in $q$ with $U^{i}(p)=0$ for $q=0$ and $U^{i}(p)=30$ for $q=1$.

\footnotetext{
${ }^{4}$ If players can implement some form of coordination, the number players should matter.
} 
The reservation probability $q_{i}^{*}$ turns out to be the value of $q$ such that an individual $i$ is indifferent between the two strategies, i.e. $U^{i}(\bar{p})=U^{i}(p)$, where in this game $U^{i}(\bar{p})=20$. Formally, $q_{i}^{*}$ is the implicit solution to:

$$
20=30 q F^{i}(q) .
$$

Finally, we notice that without the participation constraint, a risk-neutral individual would participate to the lottery if the winning probability exceeds a threshold $\hat{q}$, implicitly defined by equation:

$$
20=30 q .
$$

If $q<\hat{q}=2 / 3$, a risk-neutral, rational player will not participate to the lottery.

Figure 1 represents the left-hand terms in Eq. (3) and Eq. (4) as two functions of q. At point $A$ we get the critical winning probability in the elementary setting (individual decision, no interaction), at point $A^{\prime}$ the critical winning probability in the illiquidity game. Even in this simplified context (homogenous, risk neutral players), in presence of the participation constraint players require a higher winning probability (or a lower default probability) in order to enter the lottery. Should investors have different preferences towards risk, it would be more difficult to foresee the behavior of the pivot player (the p.d.f. of $F$ would become wider and flatter), and the minimum wining probability required to participate would rise.

The experiment presented in the next section aims at analyzing how a group of "flesh and blood" decision makers behave within the former framework. For sure, human subjects are not "homogenous"; they have their own psychological characteristics and biases (cognitive skills, various risk aversion, overconfidence/over prudence, learning abilities). The core issue is whether players do assess correctly the strategic risk, and, if not, what is the risk learning process.

\section{The Experiment}

\subsection{Experimental design}

A total of 62 subjects were recruited by the ESSEC Experimental Laboratory from the student population of the ESSEC Business School, who answered to a call for paid decision experiments. The experimental design was presented via computer interface and all interactions were comput- 


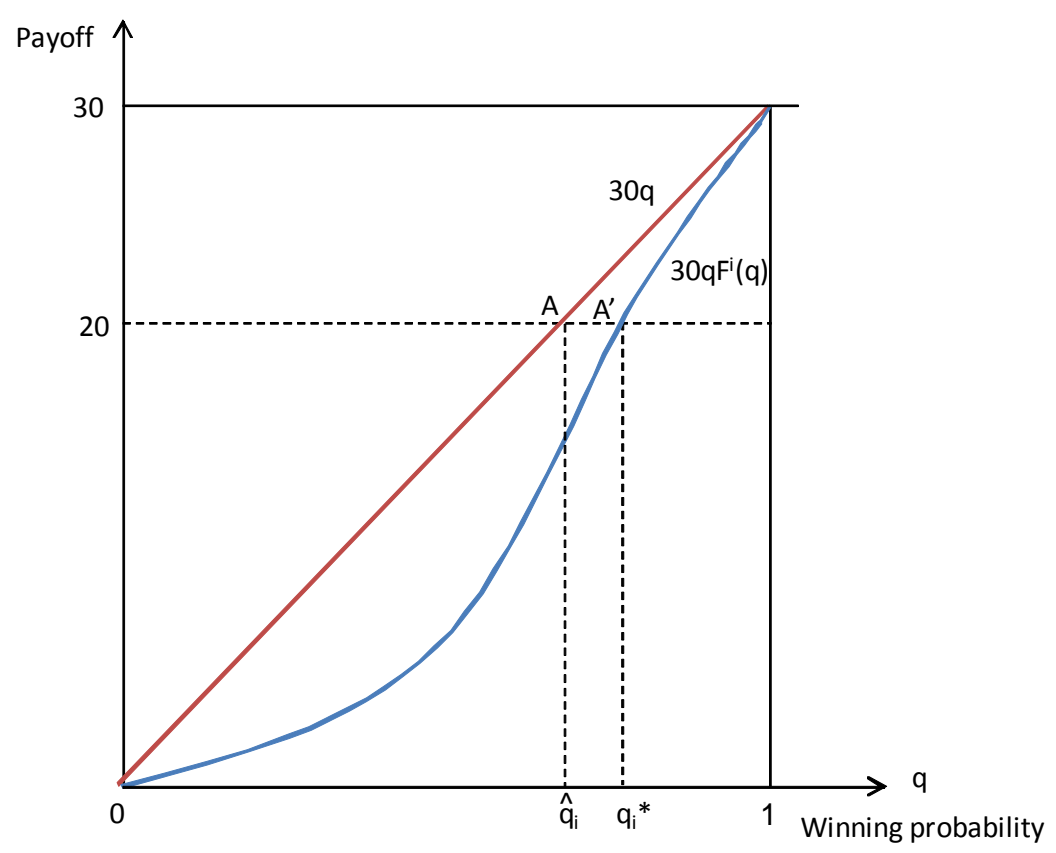

Figure 1: Illiquidity game: the winning probability thershold

erized. The programme was written in z-Tree (Fischbacher, 2007). Instructions were read aloud. Throughout the sessions students were not allowed to communicate and could not see the others' screen. [see Appendix 2 for the instructions].

At the beginning of each experiment, students were affected to a group, and the composition was kept constant over the rounds in within-subjects design.

Two conditions were implemented. Table 1 presents the schedule of the sessions. ${ }^{5}$

In the first condition $(\mathrm{C} 1)$, there is a Phase A where a group of students is faced in each round with the individual choice of investing 20 cents in the lottery $L(0 ; 30)$; the loss probability $(1-q)$ is increased in each round, rising from 0.05 to 0.70 with a step of 0.05 . In the Phase B, referred to as the "illiquidity game", the same group of students is given the choice of investing 20 cents in the lottery $L(0 ; 30)$, but this time interdependence between subject's decision is introduced in the following way: if less than $50 \%$ of the players participate in that round, participants receive nothing regardless of the lottery outcome, if $50 \%$ or more participate, they get the outcome of the lottery draw. Therefore, in the second phase players face not only the investment "intrinsic risk"

\footnotetext{
5 In both treatments, a short warming-up unpaid test (see Appendix 2) aimed to make them at ease with the basic lottery.
} 
but also strategic uncertainty related to the choice of the other component in the group.

At each round, the screen inviting the subject to participate to the game recalls the possible payoffs, indicates the "intrinsic risk" $(1-q)$ of the lottery at that round and the percent of students who played the lottery at the previous round. At the end of the round, subjects are informed about the frequency of participants, and what is their gain for that round. ${ }^{6}$

In the second condition $(\mathrm{C} 2)$, subjects were submitted only to the Phase B.

\begin{tabular}{|l|l|l|ll|}
\hline & Phase A & Phase B & Sessions \\
\hline & & & $S_{1}$ & May 2010 (9 subjects) \\
C1 & yes & yes & $S_{2}$ & June 2010 (15 subjects $)$ \\
& & & $S_{3}$ & Nov. 2010 (16 subjects $)$ \\
\hline C2 & no & yes & $S_{4}$ & April 2011 (10 subjects $)$ \\
& & & $S_{5}$ & May 2011 (12 subjects $)$ \\
\hline
\end{tabular}

Table 1. Schedule of experiments

In the "illiquidity game" (phase B), the intrinsic risk (i.e., the loss probability $1-q$ ) was varied according to a simple rule. The game starts at $t=0$ with a small default risk, $(1-q)=0.15$. As long as no illiquidity default occurs, the risk is increased by 0.05 from one round to another (like in Phase A). If an illiquidity default occurs, the same level of risk is submitted once again. Then, if illiquidity arises, the level of risk is reduced by 0.05 at the next round; if else, it is increased by 0.05 . The experiment stops after 31 rounds (when, in a pre-test study, we noticed that the decision pattern becomes stable).

The rule according to which $(1-q)$ was changed from one round to another was not made explicit. It is hard to say whether subjects were able to guess the rule over such a short experiment, and, if they did, whether they used this information to shape their behavior. ${ }^{7} \quad$ Using random draws to get the probabilities $(1-q)$ would have been a more accurate way to detect the critical "participate/do not participate" threshold, but would also have consumed much more resources.

\footnotetext{
${ }^{6}$ If the gain is zero, and the frequency of participants is larger than $50 \%$, the subject can infer that the draw was unfavorable.

7 In a dynamic set-up, for a relatively high risk, subjects might refuse to invest because they anticipate that the risk will be reduced, which would create a better opportunity to invest in the future and vice-versa.
} 
At the end of the game the software indicates the total gain of every student. A short satisfaction survey is implemented. These experiments last for 45 minutes on average. Students earned on average 13.25 euros from playing the game; the amount includes 5 euros for showing up. Group size vary depending on the number of students that answered to the call.

\subsection{Results}

Table 2 displays the summary of the results of the individual choice (Phase A): the outcome of an individual decision depends only on the loss probability $(1-q)$. Cell data indicates show the number of students who accepted to participate to the $L(0 ; 30)$ lottery, for various loss probabilities.

\begin{tabular}{|c|c|c|c|c|c|c|c|c|c|c|c|c|c|c|}
\hline$(1-q)=$ & 0.05 & 0.10 & 0.15 & 0.20 & 0.25 & 0.30 & 0.35 & 0.40 & 0.45 & 0.50 & 0.55 & 0.60 & 0.65 & 0.70 \\
\hline \multicolumn{15}{|c|}{ Session 1, May 26, 2010} \\
\hline $\mathrm{N}=9$ & 8 & 8 & 9 & 9 & 9 & 8 & 6 & 7 & 5 & 6 & 4 & 2 & 2 & 2 \\
\hline \multicolumn{15}{|c|}{ Session 2, June 9, 2010} \\
\hline $\mathrm{N}=15$ & 15 & 15 & 15 & 14 & 14 & 14 & 11 & 9 & 5 & 5 & 2 & 1 & 1 & 2 \\
\hline \multicolumn{15}{|c|}{ Session 3, Nov. 3, 2010} \\
\hline $\mathrm{N}=16$ & 14 & 15 & 16 & 15 & 15 & 13 & 10 & 8 & 9 & 8 & 7 & 1 & 2 & 0 \\
\hline
\end{tabular}

Table 2. Number of students that choose to play the lottery in the individual decision setting

We observe that less than $50 \%$ of the students accept to participate to the lottery when the loss probability (or the intrinsic risk) $(1-q)$ first exceeded 0.55 in the first and third group, and 0.45 in the second group. Notice that in a pure Von Neumann - Morgenstern decision problem, risk neutral individuals would not participate to this lottery if the risk is above 0.33 . Furthermore, we would expect that, for small gains as provided in our experiment, subjects were risk neutral. Yet, in this experiment, not participating to the lottery is associated to "inaction", while participating is associated to "action" (i.e., "do something"). Our subjects are not necessarily risk lovers (i.e., if they have the choice between two lotteries with the same expected gain, they would choose the less riskier one), but behave as if they were risk lovers because they reap a small benefit from acting rather than waiting (they love to play). This bias has no impact on the subsequent results, 
since the entry level decision ("bet 20 cents") is the same in all treatments. ${ }^{8}$

Tables 3 and 4 presents the main results of the "illiquidity game" in the Condition 1 (Phases A and B) and Condition 2 (Phase B only). Columns have two main labels: " ${ }^{\text {th }}$ default" and "r-to-m" for "return-to-market". For instance, in the column "1 ${ }^{\text {st }}$ default", cell data indicate the loss probability $(1-q)$ that triggered the first illiquidity default (i.e. less than $50 \%$ of the subjects participate to the lottery). The adjacent "r-to-m" column indicates the loss probability when $50 \%$ of the subjects or more decided to participate again (return-to-market). The same sequence is repeated three more times, for the second, third and fourth default. Between brackets we indicate the number of students who accepted to play the lottery for that "threshold" probability. In Appendix 1 we present graphs that show the evolution of the group decision during the experience (for each group).

\begin{tabular}{|c|c|c|c|c|c|c|c|c|}
\hline & $1^{s t}$ default & r-to-m & $2^{\text {nd }}$ default & r-to-m & $3^{r d}$ default & r-to-m & $4^{t h}$ default & r-to-m \\
\hline \multicolumn{9}{|c|}{ Session 1, May 26, 2010} \\
\hline $\mathrm{N}=9$ & $0.40(4)$ & $0.25(7)$ & $0.40(0)$ & $0.25(6)$ & $0.35(1)$ & $0.25(6)$ & $0.35(1)$ & $\mathrm{x}$ \\
\hline \multicolumn{9}{|c|}{ Session 2, June 9, 2010} \\
\hline $\mathrm{N}=15$ & $0.45(4)$ & $0.35(10)$ & $0.40(6)$ & $0.30(12)$ & $0.40(1)$ & $0.30(13)$ & $0.40(0)$ & $0.30(12)$ \\
\hline \multicolumn{9}{|c|}{ Session 3, Nov. 3, 2010} \\
\hline $\mathrm{N}=16$ & $0.40(7)$ & $0.25(8)$ & $0.35(6)$ & $0.25(10)$ & $0.30(7)$ & $0.25(15)$ & $0.30(2)$ & $0.25(14)$ \\
\hline
\end{tabular}

Table 3. Default and return-to-market probability thresholds $(1-q)$ in Condition 1

(Between brackets, the number of students who participate to the lottery)

\begin{tabular}{|c|c|c|c|c|c|c|c|c|}
\hline & $1^{\text {st }}$ default & r-to-m & $2^{\text {nd }}$ default & r-to-m & $3^{r d}$ default & r-to-m & $4^{t h}$ default & r-to-m \\
\hline \multicolumn{9}{|c|}{ Session 4, April 6, 2011} \\
\hline $\mathrm{N}=10$ & $0.50(2)$ & $0.35(6)$ & $0.45(2)$ & $0.40(6)$ & $0.45(2)$ & $0.40(6)$ & $0.45(1)$ & $0.40(6)$ \\
\hline \multicolumn{9}{|c|}{ Session 5, May 18, 2011} \\
\hline $\mathrm{N}=12$ & $0.55(1)$ & $0.35(7)$ & $0.45(1)$ & $0.35(8)$ & $0.45(2)$ & $0.35(11)$ & $0.45(2)$ & $\mathrm{x}$ \\
\hline
\end{tabular}

${ }^{8}$ Another explanation would involve noise in the data, in particular if subjects do not believe that the displayed probabilities were the true ones. In order to reduce such noise, subjects should have played the game many more times, but this is hard to implement in the Lab (subjects would become tired and bored). 
Table 4. Default and return-to-market probability thresholds $(1-q)$ in Condition 2

(Between brackets, the number of students who participate to the lottery)

Let us firstly analyze the data relative to the illiquidity game. The first default occurs for $(1-q)=0.40$ in groups 1 and 3 , and 0.45 in group 2; in Condition 2, it was 0.50 and 0.55 in groups 4 and 5. Once that illiquidity default occurs for the first time, subjects adopt a security attitude, and refuse to participate to the lottery until the intrinsic risk is reduced in a substantial way (at 0.25 for groups 1 and 3, 0.35 for groups 2, 4 and 5). We can state that:

R1. The first time they play the illiquidity game, subjects seem to be over-confident and accept high intrinsic risk projects. After a first default, they become "excessively prudent" and accept to participate only if the intrinsic risk is much lower. This bipolar pattern holds in both conditions.

After few defaults (not more than three), subjects manage to coordinate their strategies around an "asymptotic" threshold default probability, above which they refuse to participate to the lottery. The number of persons that coordinate their decision around this critical value increases over the rounds; after three defaults, almost all individuals in the sample coordinate their decision on that level. This coordination is explained by learning about the strategies of the other players.

R2. At the term of the learning process, (heterogenous) subjects coordinate their actions on a threshold strategy; they (almost) all accept to participate to the lottery if the intrinsic risk is below this threshold, and vice versa.

The fourth (asymptotic) default probability threshold is lower than the probability default threshold of the first default for all five sessions.

R3. At the term of the learning process, a large majority of subjects refuse to participate to the project if the intrinsic risk exceeds a threshold much lower than they accepted before the first default.

Data from the individual decision problem (C1, Phase A) can also provide some interesting insights. In this first stage, the only risk that matters is the "intrinsic risk" since there is no participation constraint. We noticed that, depending on their tastes for risk and playing the 
game, $50 \%$ or more of the subjects bet on the lottery if the intrinsic risk raised above 0.55 in groups 1 and 3 , and 0.45 in group 2 (Table 1). In the Condition 2, the first default threshold in the illiquidity game is at 0.50 for group 4 , and 0.55 for group 5 .

R4. Before a first default has occurred, subjects do not seem able to gauge well the coordination risk.

The specific coordination risk might be estimated by the difference in the risk levels where $50 \%$ of the players accept to play the lottery in the individual decision problem and the asymptotic threshold default probability in the illiquidity game. Yet, in order to rule out the carry-over effect, we should compare results from Phase A of $\mathrm{C} 1$ with Phase $\mathrm{B}$ of $\mathrm{C} 2$, knowing that results can be biased by group heterogeneity specific to between-subjects measures. With perfectly homogenous groups, the difference would be representative of the specific coordination risk. Unfortunately in our data, we cannot observe a significant difference.

\subsection{A pooled data analysis}

A simple pooled data analysis allows us to emphasize as a general pattern the systematic downwards revision in the illiquidity default thresholds. In order to do so, we report for each experiment the probabilities that triggered the first, second, third, fourth and fifth default; the order number $n$ of the default is similar here to the time dimension in standard panel data analysis.

We denote by $T D P_{s n}$ the threshold default probability corresponding to the $n^{\text {th }}$ default in session $s$, with $n=\{1,2,3,4,5\}$ and $s=\{1,2,3,4,5\}$. Data for C1 experiments (S1, S2, S3) come from Table 3, and data for $\mathrm{C} 2$ experiments $(\mathrm{S} 4, \mathrm{~S} 5)$ come from Table 4; there are 23 observations available. The five series are displayed in Figure 2, where the horizontal axis indicates the default order number (first, second, etc.) and the vertical axis indicates the threshold default probability.

We then run the regression:

$$
T D P_{s n}=F_{s}+a n+b n^{2}+\epsilon_{s n}
$$

where $F_{s}$ is the fixed effect for each session (a dummy variable), $n$ is, as already mentioned, the order number or the default, $a$ and $b$ are coefficients and $\epsilon_{s n}$ is an error term. The quadratic form is interesting since it allows for a dampening effect, representative of the convergence put forward 


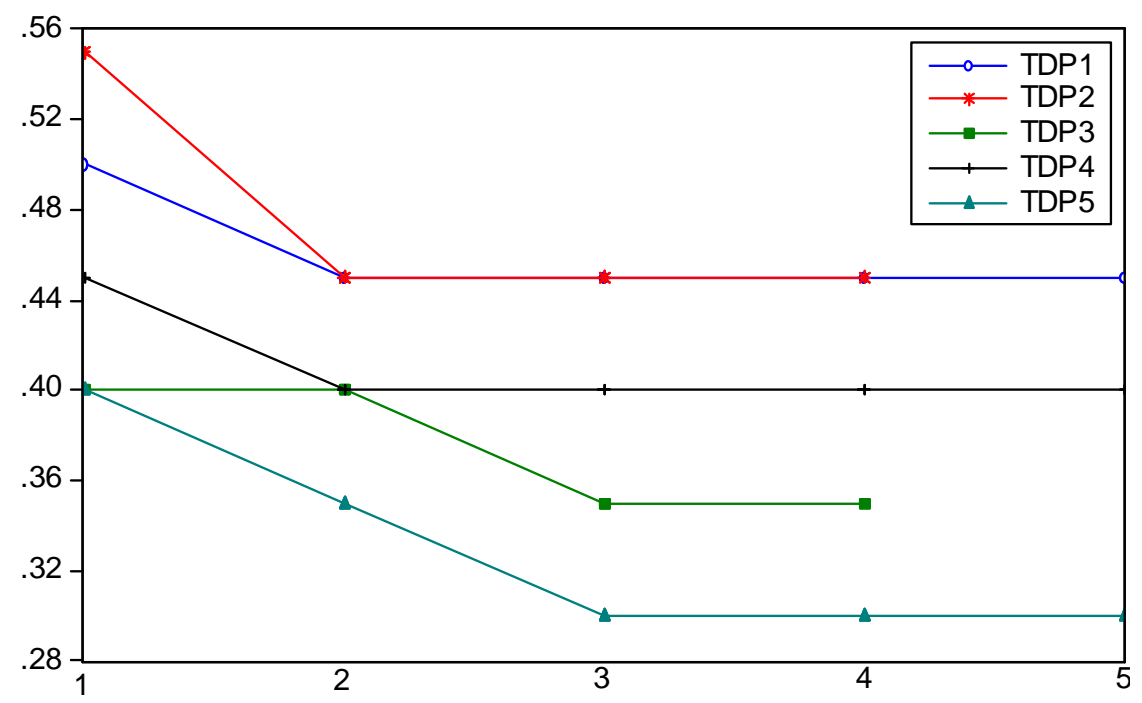

Figure 2: Threshold default probability in the 5 sessions

in the descriptive statistics.

The OLS estimation of Equation (5) are displayed in Table 4. The dependent variable is the threshold default probability $T D P_{s n}$. Model 1 is a special case of model 2, where we omit the quadratic term.

\begin{tabular}{|l|l|l|}
\hline Variable & MODEL 1 & MODEL 2 \\
\hline $\mathrm{n}$ & $-0.0175^{* * *}$ & $-0.0700^{* * *}$ \\
\hline $\mathrm{n}^{\wedge} 2$ & - & $0.0091^{* * *}$ \\
\hline \multicolumn{2}{|l|}{ Fixed effects (cross section) } \\
\hline F1 & $0.419^{* * *}$ & $0.482^{* * *}$ \\
\hline $\mathrm{F} 2$ & $0.462^{* * *}$ & $0.520^{* * *}$ \\
\hline $\mathrm{F} 3$ & $0.383^{* * *}$ & $0.440^{* * *}$ \\
\hline F4 & $0.513^{* * *}$ & $0.560^{* * *}$ \\
\hline F5 & $0.519^{* * *}$ & $0.582^{* * *}$ \\
\hline \multicolumn{2}{|l|}{} \\
\hline Nb obs. (unbalanced) & 23 & 23 \\
\hline R 2 -Adjusted & 0.857 & 0.923 \\
\hline Proba(F-stat) & 0.00 & 0.00 \\
\hline
\end{tabular}


$(* * *)$ indicates significance at $1 \%$.

Table 5. Output of the regression model

As expected, the coefficient $a$ is negative in both models: players revise downwards their default thresholds. In model 2, the small and positive coefficient of the quadratic term is also consistent with our expectations: after several successive defaults, the strength of the adjustment is declining. From model 1, we notice that from the first to the fourth default, on average the default threshold would vary by -0.0525 , i.e. $11 \%$ below the average first default threshold. Model 2 would suggest that after three more defaults, the default threshold would vary by -0.0735 , i.e., $14 \%$ below the average first default threshold.

Fixed effects in condition C2 (F4 and F5) are systematically higher than in treatment C1 (F1, F2, F3), indicating that the carry over effect specific to $\mathrm{C} 1$ is not negligible (subjects seem to be more prudent if they firstly performed the individual decision test).

\section{Conclusion and some policy implications}

The Asian crisis of 1997, the Argentinean default of 2001, the 2007-2009 Great Recession, and the recent turmoil in Euro-area public debt markets are all representative episodes of the dramatic consequences of sudden investors' panic. While anyone would agree that in a financially globalized world illiquidity tends to become a major factor of economic instability, research on the origin and mechanisms of illiquidity is relatively scarce.

This paper develops an experiment to study how strategic uncertainty contributes to the total risk of a collective investment project. In the experiment, the failure of the project can be brought about either by an internal, specific risk or by poor coordination of investors. Results confirm the insidious nature of illiquidity: as long as a first coordination default does not happen, subjects appear to be "overconfident": a majority of investors accept to participate to projects featuring a high intrinsic risk. But after a first illiquidity default, they fall in the opposite direction and become extremely cautious; they come back to markets only if the intrinsic risk is much reduced. In the experiment, it took a small number of such default cycles to reach a threshold default probability around which investors coordinate their actions; this fast learning process might be 
explained by the risk adjustment rule that favoured cyclical behavior. In a more rigorous setting, subject should have been submitted to loss probabilities drawn at random. The learning process would have been slower; unfortunately this alternative methodology is difficult to implement, since it requires much more observations.

One peculiar feature of our experiment is that a majority of subjects behave as if they were risk lovers. This can be explained by the incentive scheme, where subjects get a small endowment at the beginning of each iteration, and are asked to make a bet on a lottery. In the Lab, making a bet is associated to "taking an action", as opposed to "doing nothing". For sure, our subjects, made up of young students, have a natural bias to act rather than to wait. However, this "acting bias" does not challenge our main findings, since the same subjects played the same game under various conditions and for several times; whatever their incentive to participate to the lottery, their behavior changes when strategic uncertainty is introduced.

Further research might test the game for varying participation thresholds as in Heinemann et al. (2009), or make this participation threshold endogenous. The intrinsic risk of default was known, while in real life investors can be subject to ambiguity. The advantage of this simple experiment is that it can disentangle the illiquidity risk (stemming from poor coordination) from the total risk of an investment project.

Our findings might shed some light on several policy issues. Immediately after a first illiquidity default, subjects in our experiment adopted a security stance and refused to lend until the intrinsic risk declined in a substantial way. This second effect can explain a phenomenon of crisis hysteresis. Before the Great Recession, banks were financing many high risk projects. Yet after the crisis, the same banks were criticized on ground that they were too cautious, and did not lend enough. Our analysis points out that this extremely prudent attitude is the normal behavioral response after an illiquidity-driven crisis.

Today there is a large debate on what should be the appropriate response of the ECB to the Euro debt crisis. In the light of this paper, as long as the Euro area does not possess a genuine "lender-of-last-resort" (like the US or the UK), investors in Euro area public debts must consider both the insolvency risk and the illiquidity risk. No wander that in the 2010-2012 period, interest 
rates on 10-year T-bonds in Spain and Italy spiked so often, and only the commitment of the ECB, in September 2012, to bail out distressed governements managed to bring some relief to the Euro bond markets.

\section{References}

Besancenot, Damien, Kim Huynh and Radu Vranceanu, 2004, Default on sustainable public debt: Illiquidity suspect convicted, Economics Letters, 82, pp. 205-211.

Brunnermeier, Marcus K., 2009, Deciphering the liquidity and credit crunch 2007-2008, Journal of Economic Perspectives, 23, 1, pp. 77-100.

Bryant, John, 1983, A simple rational expectations Keynes-type model, Quarterly Journal of Economics, 98, 3, pp. 525-528.

Camerer, Colin, F., 2003, Behavioral Game Theory, Princeton University Press, Princeton.

Carlsson, Hans and Eric van Damme, 1993, Global games and equilibrium selection, Econometrica, 61, 5, pp. 989-1018.

Devetag, Giovanna and Andreas Ortmann, 2007, When and why? A critical survey on coordination failure in the laboratory, Experimental Economics, 10, 3, pp. 331-344

Diamond, Douglas and Philip H. Dybvig, 1983, Bank runs, liquidity, and deposit insurance, Journal of Political Economy, 91, 3, pp. 401-419.

Fischbacher, Urs, 2007, z-Tree: Zurich toolbox for ready-made economic experiments, Experimental Economics, 10, pp. 171-178.

Garratt, Rod and Todd Keister, 2009, Banks runs as coordination failures, Journal of Economic Behavior and Organization, 71, pp. 300-317.

Heinemann, Frank, Roesemarie Nagel and Peter Ockenfels, 2004, The theory of global games on test: Experimental analysis of coordination games with public and private information, Econometrica, 72, 5, pp. 1583-1599.

Heinemann, Frank, 2000, Unique equilibrium in a model of self-fulfilling currency attacks, American Economic Review, 90, pp. 316-318.

Heinemann, Frank, Rosemarie Nagel, Peter Ockenfels, 2009, Measuring strategic uncertainty in coordination games, Review of Economic Studies, 76 (1) pp. 181-221

Madiès, Philippe, 2006, An experimental exploration of self-fulfilling banking panics: Their occurrence, persistence and prevention, Journal of Business, 2006, 79, 4, pp. 1831-1866.

Miller, Marcus and Joseph E. Stiglitz, 2010, Leverage and asset bubbles: averting Armagedon with Chapter 11? Economic Journal, 120, pp. 500-518.

Morris, Stephen and Hyung Song Shin, 2009, Illiquidity component of credit risk, mimeo, Princeton.

Morris, Stephen and Hyung Song Shin, 2002, Global games: Theory and applications, In: M. Dewatripont, L. Hansen, S. Turnovsky, Eds., Advances in Economics and Econometrics, Cambridge University Press, UK, pp. 56-144.

Morris, Stephen and Hyung Song Shin, 1998, Unique equilibrium in a model of self-fulfilling currency attacks, American Economic Review, 88, pp. 587-597. 
Rochet, Jean-Charles and Xavier Vives, 2004, Coordination failures and the lender of last resort: Was Bagehot right after all ?, Journal of the European Economic Association, 2, 6, pp. 1116-1147.

Schotter, Andrew and Tanju Yorulmazer, 2009, On the severity of bank runs: An experimental study, Journal of Financial Intermediation, 18, 2, pp. 217-241

Summers, Laurence, H., 2000, International financial crises: Causes, prevention, and cures, American Economic Review, 90, 2, pp. 1-16.

Van Huyck, John B., Raymond C. Battalio and Richard O. Beil, 1990, Tacit coordination games, strategic uncertainty and coordination failure, American Economic Review, 80, 1, pp. $234-248$. 


\section{Appendix 1. Data for Phase B (illiquidity game) experi- ments}

[Appendix 1 and 2 might be made availbe online only, not in a printed version]

The figures below indicate the evolution of illiquidity defaults depending on the level of risk.

The computer chooses the level of risk according to the rule presented in Figure 2.

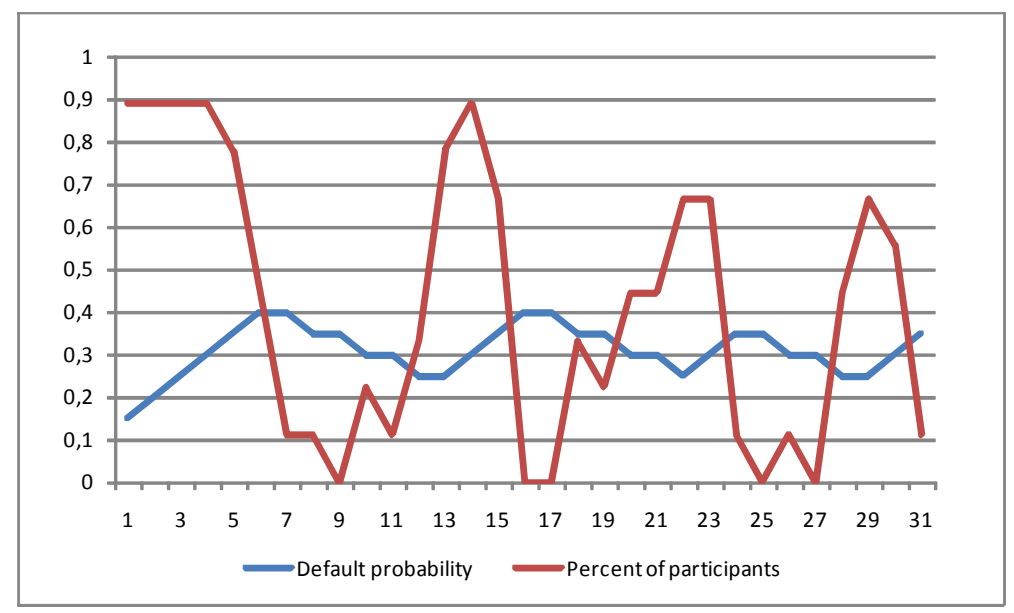

Experience 26-05-2010 ( $\mathrm{N}=9)$

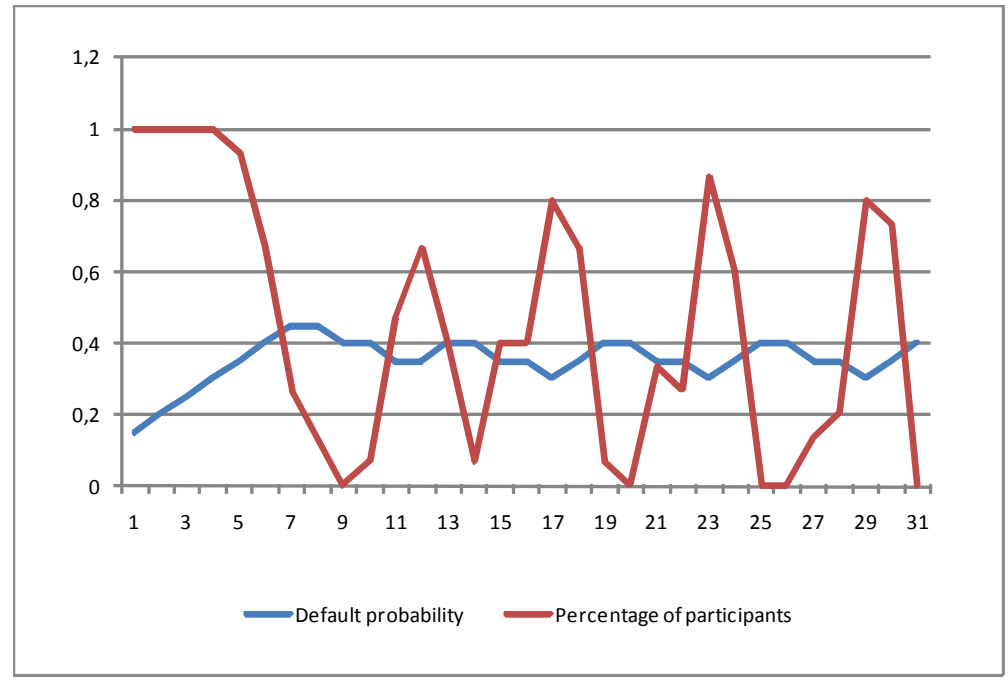

Experience 09-06-2010 (N=15) 


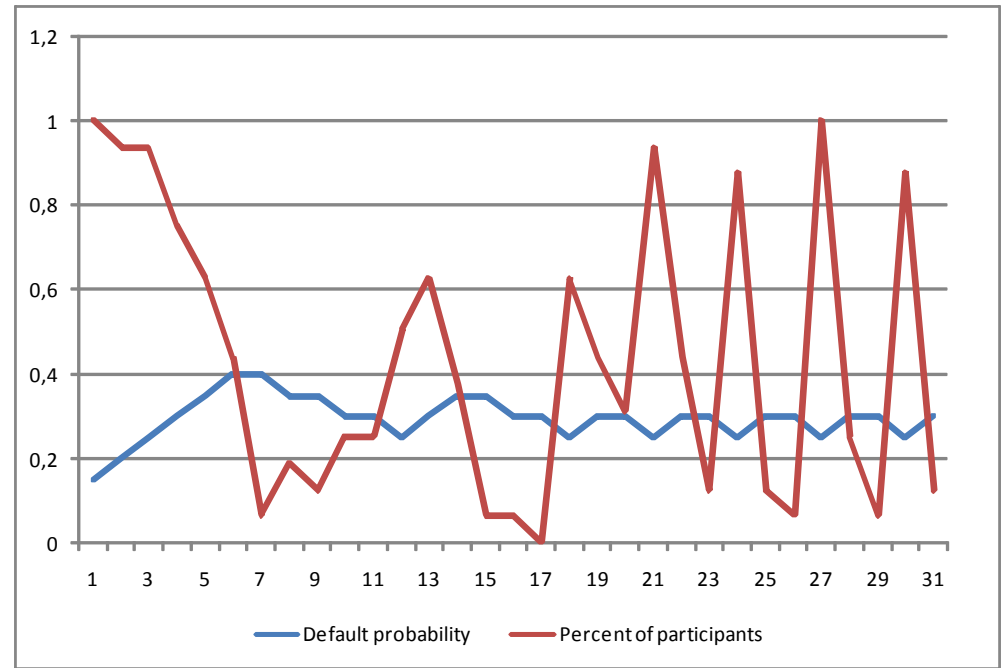

Experience 3-11-2010 ( $\mathrm{N}=16)$

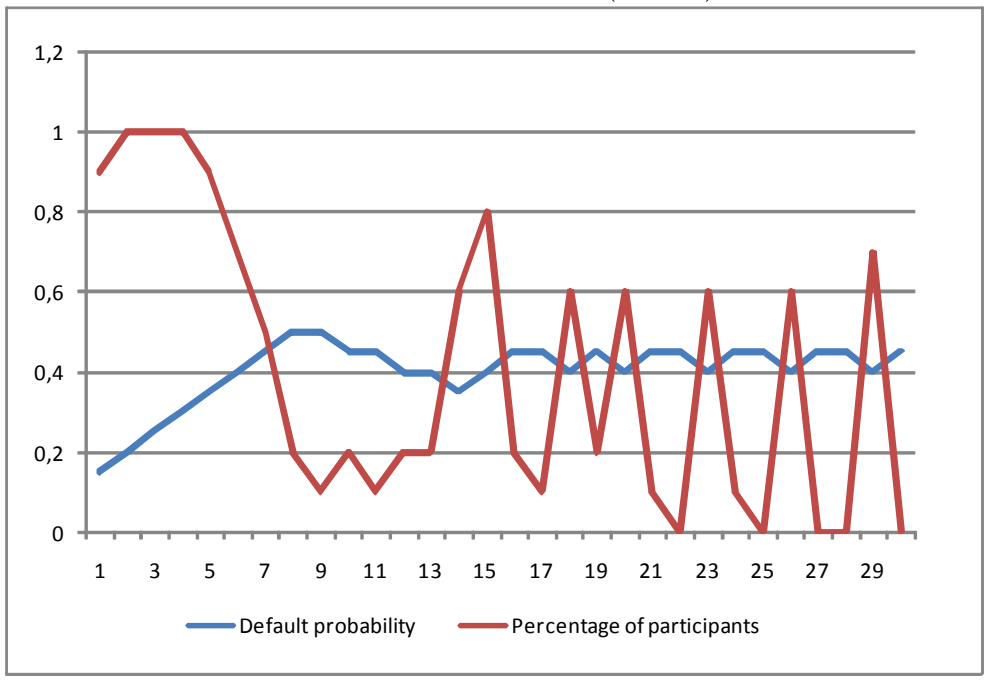

Experience 6-04-2011 ( $\mathrm{N}=10)$

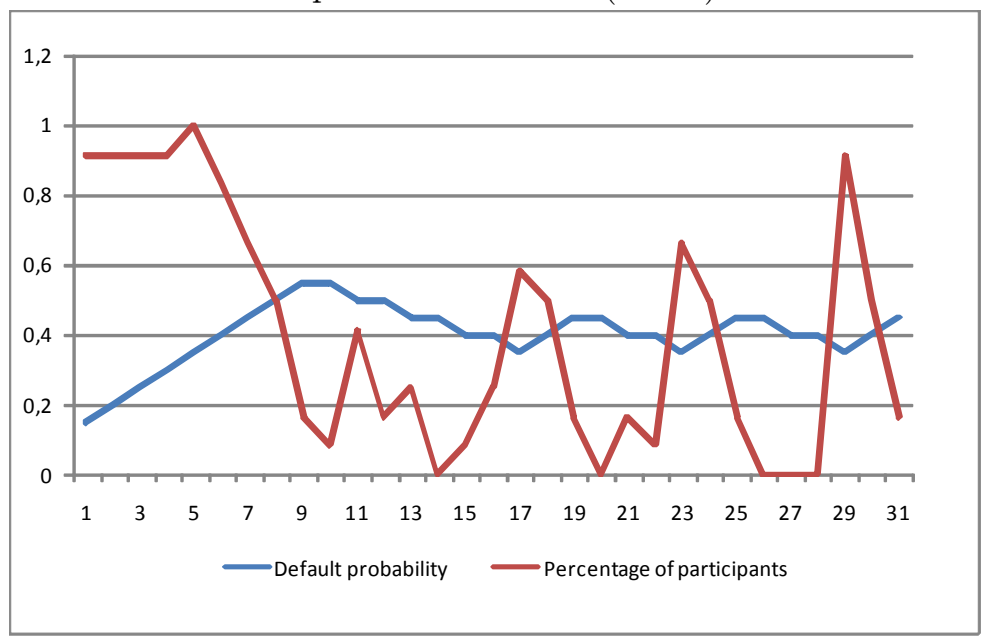

Experience 18-05-2011 (N=12) 


\section{Appendix 2. Instructions for the C1 experiment ${ }^{9}$}

Screen 1. Welcome to the ESSEC Experimental Laboratory. This experiment aims at studying the interaction between two risks and their consequences on the individuals' decisions. There will be two stages, one warming-up non-paid stage, and a paid stage. Pay attention please: the game progresses when the last player take his/her decision.

\section{THE WARMING-UP TEST}

Screen 2. Lotteries. It costs you 20 cents to participate to a lottery. The lottery will allow you either to gain 30 cents or nothing.

Screens 3-4-5. Would you pay 20 cents to participate to a lottery that brings you 30 cents with a probability of $60 \%(50 \%, 40 \%)$ and 0 cents with a probability of $40 \%(50 \%, 60 \%)$ ? Yes/No.

\section{THE INDIVIDUAL DECISION TEST}

Screen 6. From now on the experiment will be paid. You receive the money at the beginning of each game and the decisions are material.

Screen 7. You will receive 20 cents at each round of the game. You can use them to buy the right to play a lottery. If you play the lottery, you lose and the gain is zero or you can win 30 cents. The loss probability will be displayed on the screen. This is the true probability used by the computer to pick the outcome. If you answer Yes to the question "do you accept to play the lottery" the participation fee is charged and you will benefit of the outcome of the lottery. Payment rule: if you do not play, the 20 cents are kept on your account. If you play and win, your account is credited of 30 cents. If you play an loose, your account is credited of 0 cents.

Screens 8 and next. Number of the actual round [1 to 14$]$. The loss probability is $[1-q] .{ }^{10}$ "Do you accept to play this lottery ?" Yes/No.

Screens 8' and next. Outcome of the round. You decided not to play; your gain is [20]. OR You decided to play; you gain is [0 or 30].

\footnotetext{
${ }^{9}$ Original instructions in French.

${ }^{10}$ From one round to another, $1-q$ will be increased by 0.05 , from 0.05 to 0.70 .
} 


\section{THE "ILLIQUIDITY GAME"}

Screen 9. In this configuration the outcome of the game depends on both your choice and the choice of the group members.

As before, you get 20 cents at each round. You can use them to buy the right to play a lottery that delivers either 30 cents or 0 cents. As before, this external probability of the zero payoff is indicated at each round.

At difference with the previous game:

- if at least [50\%] of the players in the group participate, the loss / win outcome depends only on this external probability.

- if less than [50\%] of the players participate to the lottery, the gain is [zero] for all players who participated to the lottery.

Slide 10. Examples

Example 1. There are 20 subjects. The displayed probability of loss is $[1-q]$. For this level of risk, 6 players participate, 14 do not. Less than [50\%] participate.

Outcome: All those who participate get zero, all those who did not keep the 20 cents.

Example 2. There are 20 subjects. The displayed probability of loss is $[1-q]$. For this level of risk, 18 players participate, 2 do not. More than [50\%] participate.

Outcome: Those who did not participate keep the 20 cents. Those who participate get 30 cents with a probability $[q]$ and zero with a probability $[1-q]$.

Screens 11 and next. Number of the actual round [1 to 31$]$. The loss probability is $[1-q] .{ }^{11}$ At the former round, the percentage of subjects that participated to the lottery was of [y\%]. "Do you accept to play the lottery ?" Yes/No.

Screens 11' and next. Outcome of that round. The loss probability was $[1-q]$. You decided to participate (not to participate). The percentage of participants is [z\%], i.e. more (less) than [50\%]. Your gain is [30 or zero].

\footnotetext{
11 From one round to another, this probability will vary starting from 0.15 according to the rule described in Section 2 .
} 
Screen 12. Your total gain for the experieemnt is [A] euros. Thank you for having participate to this experiment. 
ESSEC Business School Avenue Bernard Hirsch BP 50105

95021 Cergy-Pontoise Cedex

France

Tél. +33(0)134433000

$\mathrm{Fax}+33(0) 134433001$

www.essec.fr

\section{ESSEC Executive Education} CNIT BP 230

92053 Paris-La Défense France

Têl. +33(0)146924900

Fax +33(0)1 46924990

http://formation.essec.fr

ESSEC Business School

Singapore Campus

100 Victoria Street

National Library Building \# 13-02

Singapore 188064

essecasia@essec.fr

Tél. +6568849780

Fax +6568849781

www.essec.edu

Informations

Alison Bougi

+33 (0)134433358

bougi@essec.fr

www.essec.fr

research.center@essec.fr

ISSN 1291-9616 